\title{
“TODO DESCONSTRUIDINHO”: JOVENS LÍDERES DO MOVIMENTO ESTUDANTIL OCUPA TUDO RS
}

\author{
“TODO DESCONSTRUIDINHO”: YOUNG LEADERS OF THE SCHOOL COLLECTIVE OCCUPATION MOVEMENT \\ OCUPA TUDO RS
}

“TODO DESCONSTRUIDINHO”: JÓVENES LÍDERES DEL MOVIMIENTO ESTUDIANTIL OCUPA TODO RS

\author{
MEDAETS, Chantal ${ }^{1}$ \\ MÉZIÉ, Nadège ${ }^{2}$ \\ CARVALHO, Isabel Cristina de Moura ${ }^{3}$ ii
}

\begin{abstract}
RESUMO
O artigo tem como objetivo apresentar narrativas e memórias de líderes do movimento de ocupação das escolas ocorrido no Rio Grande do Sul em 2016. Do ponto de vista metodológico, o estudo se baseou em uma etnografia, e em entrevistas realizadas naquela época e um ano depois. Combinando dados sobre o grupo e o contexto do movimento com detalhes da trajetória individual de dois líderes, os resultados mostram aspectos menos abordados na crescente literatura sobre a onda de ocupações de escolas de 2016, como os "rachas" internos ao movimento e a mobilização e o reconhecimento de competências adquiridas no contexto da participação religiosa. A análise traz também à tona as aprendizagens ligadas à prática militante e a importância da presença feminina e feminista neste movimento social, dialogando com a literatura antropológica e sociológica sobre movimentos sociais.
\end{abstract}

Palavras-chave: Juventude. Militância política. Memórias. Ocupação. Feminismo.

\section{ABSTRACT}

The article presents the portraits of two leaders of a school collective occupation movement occurred in the state of Rio Grande do Sul (Brazil), in 2016. The work is based on ethnographic fieldwork and interviews. Combining data on the group and the context of the movement with details of the individual trajectory of two leaders, the results show aspects less addressed in the growing literature on the Brazilian social movement of schools' occupations, such as its internal fractures and mobilization and recognition of skills acquired in the context of religious participation. Analysis also describes learnings related to the activist activity and the significant participation of young women and feminists in this social movement, dialoguing with anthropological and sociological research on social movements.

Keywords: Youth. Political activism. Memories. Social movement. Feminism.

\section{RESUMEN}

El artículo tiene como objetivo presentar narrativas y memorias de líderes del movimiento de ocupación de las escuelas ocurrido en Rio Grande do Sul en 2016. El estudio se basó en una etnografía y en entrevistas realizadas en aquella época y un año después. Combinando datos sobre el grupo y el contexto del movimiento con detalles de la trayectoria individual de dos líderes, los resultados muestran aspectos menos abordados en la creciente literatura sobre las ocupaciones de escuelas en Brasil, como las fracturas internas al movimiento y la movilización y el reconocimiento de competencias adquiridas en el contexto de la participación religiosa. El análisis muestra también los aprendizajes vinculados a la práctica militante y la importancia de la presencia femenina y feminista en este movimiento social, dialogando con la literatura antropológica y sociológica sobre movimientos sociales.

Palabras clave: juventude. Militancia política. Recuerdos. Ocupacíon. Feminismo.

\footnotetext{
1 Universidade Estadual de Campinas - Unicamp - São Paulo - Brasil

2 Pontifícia Universidade Católica de São Paulo - PUCSP - São Paulo - Brasil

3 Universidade Federal de São Paulo - Unifesp - São Paulo - Brasil
} 


\section{INTRODUÇÃO}

O movimento de ocupação de escolas ocorrido entre maio e junho de 2016 no estado do Rio Grande do Sul foi, para muitos jovens que o integraram, uma abertura e primeira experiência na militância estudantil e na militância tout court. Participar de assembleias, de "atos" (manifestações de rua), elaborar frases de efeito, dialogar com e confrontar pais, professores, políticos, jornalistas, colaborar com e também se confrontar a outros participantes do movimento, assumir diferentes funções no cotidiano da ocupação: ações que permitiram uma apropriação progressiva dos códigos e "boas maneiras" de um tipo específico de militância política, a militância em movimentos que recorrem à ocupação do espaço público como modo de ação. Desde os anos 2000, esses movimentos têm se multiplicado em diferentes lugares do mundo (HARVEY et al., 2012; PICKERILL et al., 2015).

Outros jovens do movimento gaúcho, com uma "carreira militante" (FILLIEULE, 2009; VENDRAMIN, 2003) já mais estabelecida, puseram ali em prática ideias e um repertório de ações e saberes que vinham construindo, confrontando essas ideias às de outros e ao dia a dia particular que implica uma ocupação. Haviam adquirido essa experiência acompanhando a militância de familiares, participando ou presidindo grêmios estudantis, conselhos escolares, integrando partidos políticos ou entidades estudantis, ou ainda, participando ativamente na sua igreja. As mais de 150 escolas estaduais ocupadas, sobretudo em Porto Alegre, foram assim um espaço de experimentação, uma "segunda casa", como diziam os jovens ocupantes, mas uma casa na qual eles eram os responsáveis pela elaboração das regras de convivência e de atuação militante. Os secundaristas do Rio Grande do Sul, como aqueles dos mais de 20 estados brasileiros por onde o movimento se estendeu em 2016, protestavam contra as más condições de ensino e se inspiraram das ocupações de escolas ocorridas no Chile em 2006 e na cidade de São Paulo em 2015.

Enquanto duraram as ocupações no Rio Grande do Sul, de 11 de maio a 21 de junho de 2016, nós participamos das atividades promovidas por um grupo de aproximadamente 30 alunos que ocuparam a escola que vamos chamar aqui de Toledo Barbosa, realizando uma etnografia da ocupação nessa escola. As fontes que usamos para contribuir com a elaboração de uma história do tempo presente deste movimento social são, portanto, aquelas oriundas do campo da antropologia da educação: observação participante cotidiana das atividades do grupo estudado (durante a ocupação) e entrevistas em profundidade. Realizamos duas entrevistas individuais com 15 jovens durante a ocupação e realizamos também uma entrevista com cada um deles um ano após o término do movimento. As primeiras entrevistas buscavam captar suas percepções "à quente", durante o movimento, e vinham completar os dados oriundos das observações. As últimas tiveram por objetivo acessar as memórias dos participantes sobre o que viveram e acompanhar o desenrolar de suas trajetórias.

Neste artigo, escolhemos apresentar os dados na forma de retratos de dois dos líderes desse movimento social, Caio e Valentina . Em outro texto (MEDAETS et al., 2018), retratamos outros quatro alunos da Toledo que participaram da sua ocupação sem assumir um papel de liderança. Ali, tratamos do dia a dia da ocupação e do entrelaçamento entre vida privada e experiência militante, dialogando 
com o campo da antropologia das emoções. No presente artigo, além das particularidades das trajetórias de Valentina e Caio, através de seus retratos, abordaremos outros aspectos importantes na experiência vivida pelo conjunto de secundaristas que foram nossos interlocutores. Com Caio, trataremos das aprendizagens ligadas à participação política e, especialmente, da apreensão que muitos desses jovens constroem, progressivamente, da diversidade de atores e posições existentes no interior da militância estudantil - os "rachas" internos ao movimento. Com Valentina, veremos o papel central que tiveram as meninas no movimento e a importância da presença de ideias feministas nele. Mostraremos também que as competências que esta jovem adquiriu participando ativamente da vida da igreja evangélica que frequenta foram fundamentais para que ela fosse reconhecida como liderança, como uma "mãe da ocupação". Tanto descrições sobre as fraturas internas ao movimento, quanto sobre a diversidade de espaços formativos dos jovens (como a igreja) são temas pouco abordados pela crescente literatura acadêmica que trata do movimento das escolas ocupadas no Brasil e constituem uma contribuição deste trabalho para a compreensão de facetas menos olhadas deste movimento social.

Por fim, sugerimos que as ocupações não representaram só uma luta por transformações das escolas e da política educacional, mas foram também um importante propulsor de transformações pessoais: os jovens buscavam transformar-se a si mesmos ("se desconstruir") e incentivar a transformação ("desconstrução") dos membros da "família" da ocupação.

\section{CAIO, QUEIMANDO BANDEIRAS}

Incontestavelmente um dos líderes do movimento Ocupa Tudo RS, não apenas na Toledo, Caio (16 anos, 3o ano do ensino médio durante a ocupação) não frequentava a escola antes da ocupação. "Basicamente, eu tava atirado, completamente desmotivado", ele diz. Alto, cabelos no ombro, postura de quem sabe que atrai os olhares das meninas, Caio cursou até o nono ano numa escola particular onde tinha bolsa de estudos e não via sentido em assistir às aulas na Toledo. Para tentar entrar na faculdade que almejava, medicina, Caio e sua mãe, com quem morava e ainda mora, haviam previsto que ele se matriculasse em um cursinho no segundo semestre de 2016 . Enquanto isso não acontecia, e antes dele "se apaixonar" pela militância, Caio se sentia profundamente entediado: "Eu não fazia nada. Basicamente minha vida era ficar em casa. Fumava, ia pro trabalho, chegava em casa, fumava mais um pouco, ia dormir, e era isso".

Na convivência com os colegas da ocupação, Caio dizia ter se achado: "Eu não tinha conversa cabeça como essas que a gente tem aqui dentro há muito tempo! Nossa... Tudo a gente fala, conversa, discute, debate. Coisas importantes da sociedade, das nossas vidas, sabe? É muito legal, eu nem sei explicar. Isso aqui me abriu, assim, um brilho nos olhos." Carla (16 anos, 20 ano do ensino médio durante a ocupação), sentada ao lado de Caio com um copo de Nescau na mão, completa: "A situação é um lixo. Mas é muito bom ter um propósito. Muito." 
Além da força emocional da convivência, do grupo percebido como "família", que marca o discurso de todos jovens com quem conversamos (MEDAETS et al., 2018), o que eles também mencionam como motivador da participação, o que fez Caio "se apegar ao movimento" como ele dizia, era justamente o sentimento de indignação. Indignação, claro, com a política de educação do governo (estadual e federal), mas também, e talvez no caso de Caio e de outros ocupantes, indignação acima de tudo com o que aprenderam sobre o próprio movimento secundarista e o papel das "entidades estudantis", como a UNE, UBES, UGES, UMESPA, UEE, UEE-Livre, JUNTOS! ou UJS . Caio e diversos outros militantes secundaristas têm uma visão extremamente crítica dessas entidades, o que os levou a criar, no início das ocupações, o CEI - Comitê de Escolas Independentes : "É que as entidades têm uma relação com o governo né? Então é muito complicado, porque a meu ver, tem dinheiro por trás disso, entende? Tem repasses." Caio continua, dando ênfase ao que percebe como aprendizagens da experiência militante:

Foram coisas que eu fui realmente descobrindo, aprendendo, conversando com pessoas mais experientes em militância. Pessoas que realmente conhecem essas entidades, militavam por elas e hoje deixaram de militar por ver o que elas representam, o que elas são. Porque, na verdade, elas representam elas mesmas e não os estudantes secundaristas. Por isso que nós nos tornamos independentes. Porque as entidades são assim, ridículas, ridículas...

As brigas entre jovens ocupantes de escolas ditas "independentes" (ou "de oposição"), representadas pelo $\mathrm{CEI}$, e aqueles oriundos de escolas também ocupadas, mas vinculadas à entidades, ocupavam boa parte dos comentários dos nossos interlocutores. Os representantes das entidades eram acusados de serem coniventes ou não suficientemente combativos face aos representantes do Estado, de serem "pelegos" e "traidores". Em sentido inverso, os representantes de entidades acusavam os "independentes" de serem "fascistas", "intransigentes" e "ingênuos". As reações ao acordo de desocupação assinado entre representantes das entidades e da Secretaria Estadual de Educação em 14 de junho, dão o tom da discórdia:

A União Brasileira dos Estudantes Secundaristas (dirigida pela UJS) GOLPEOU os estudantes que ocupam as escolas no Rio Grande do Sul. Hoje, que era para ser um dia histórico, a Entidade conseguiu jogar no lixo um mês inteiro de luta. (...) A UBES/UJS E O JUNTOS!, HOJE, CUSPIRAM NA CARA DOS ESTUDANTES E FECHARAM UM ACORDO INDEVIDO, IMORAL E ILEGÍTIMO. (Trechos de um post de 14 de junho na página Facebook do CEl. Maiúsculas no post original)

Após esse acordo, os ocupantes de escolas representadas por entidades "entregaram as chaves" e desocuparam. Já as escolas "independentes", continuaram ocupadas por mais uma semana. Para marcar a recusa do acordo assinado pelas entidades, no dia 15 de junho, aproximadamente 40 integrantes do CEI, dentre os quais vários alunos da Toledo - e, em ponta de lança, Caio - ocuparam o prédio da Secretaria da Fazenda (SEFAZE). Em consequência, os alunos maiores de idade, além de dois jornalistas, foram presos. Liberados no dia seguinte, eles continuam até hoje respondendo processo por dano qualificado contra o patrimônio do Estado.

No dia seguinte, em mais um ato, Caio queimou em público uma camiseta da UMESPA. Em outras manifestações, ele já havia queimado duas bandeiras de entidades (da UGES e UMESPA), a 
primeira carta-proposta feita pela Secretaria de Educação aos ocupantes e um boneco do governador. Sua postura combativa e provocativa era admirada pelos outros ocupantes, "as nossas atas de entrada e saída [registro que os ocupantes faziam de pessoas em entravam e saíam da escola a cada dia], a gente queima em homenagem ao Caio", contou André (17 anos, $2^{\circ}$ ano do ensino médio durante a ocupação). "Dentro dos movimentos, sempre tem que ter uma pessoa que age mais forte, assim, e acaba virando um exemplo... E o Caio é isso. Ele virou um líder aqui”, explicou Carla.

Em 21 de junho, um novo acordo de desocupação foi assinado entre o CEI e Secretaria Estadual de Educação. Caio e a presidente do grêmio da Toledo, Valentina, representavam a escola para a assinatura. Além dos pontos já obtidos pela negociação entre o governo e as entidades, o novo acordo obteve uma liberação suplementar de verbas emergenciais que foram destinadas às escolas "independentes" e garantiu que os alunos destas escolas tivessem acesso à $50 \%$ das cadeiras destinadas a estudantes no recém criado Fórum Permanente pela Educação. Para o jornal Correio do Povo, os estudantes disseram considerar essa uma "vitória parcial" . Nas conversas entre si e conosco, estavam radiantes.

\section{A APRENDIZAGEM DO POLITICO}

A militância política, como toda competência social, não emerge espontaneamente, mas depende de um processo de aprendizagem. Durante as ocupações, os jovens se apropriaram de um "repertório de ações coletivas comuns" (TILLY, 1995) que eles partilhavam com outros movimentos de ocupações de escolas, sobretudo aqueles ocorridos no Chile, em 2006, e no estado de São Paulo em 2015. O manual Como ocupar um colégio? que reunia ensinamentos dos estudantes chilenos (e argentinos), e o filme Isso aqui vai virar o Chile, que retrata as ocupações em São Paulo, eram sistematicamente citados por nossos interlocutores. Essas experiências (do Chile e de São Paulo), por sua vez, se inscrevem numa série de movimentos contestatórios recentes, que recorrem à ocupação de espaços públicos, sobretudo de praças. Partilham com eles princípios (não filiação a partidos políticos; busca por relações horizontais; reflexão contínua sobre suas ações), mas também um vocabulário e modos operatórios bastante concretos.

Além de terem dialogado com esse repertório transnacional de práticas militantes, os jovens que participaram das ocupações no Rio Grande do Sul aprenderam a mapear e entender melhor o conjunto de instituições e atores em ação no seu espaço, ali onde estavam. Esse espaço foi se expandido à medida que os jovens circulavam por diferentes instituições e interagiam com diversos tipos de pessoas: secretarias, representantes do governo estadual, sindicatos, entidades estudantis, partidos e homens políticos de diferentes tendências, advogados, procuradores, juízes, as diferentes "forças de ordem" (brigada militar, polícia civil, guarda municipal). Quem, dentro dessa rede de pessoas e instituições, são ou podem vir a ser, aliados? Quem são inimigos com os quais o único diálogo possível é a confrontação? Com quem se pode fazer alianças estratégicas mas mantendo um - ou dois... - pés atrás? Como disse Caio: "eu não fazia ideia desses esquemas todos. Eu tô aprendendo coisas aqui 
que talvez eu nunca aprendesse na minha vida se não fosse isso, algo realmente incrível. Isso aqui que a gente tá vivendo é uma aula imensa de cidadania tá ligado? Uma aula assim muito forte."

Como percebe-se no retrato deste jovem, do conjunto dessa rede, um tipo de instituição captou especialmente a atenção dos jovens, suscitando reações e inúmeros discursos de forte carga emocional: as "entidades" estudantis (UBES, UMESPA, UGES, etc.). Essas entidades são instâncias de representação estudantil, com diretorias eleitas, e são responsáveis pela emissão das carteirinhas estudantis que garantem a meia tarifa em passes de transporte público, shows e cinemas. Por esse serviço, elas cobram valores que, somados aos "repasses" (de órgãos governamentais) mencionados por Caio, as permitem manter uma estrutura de prédios e funcionários. As denúncias de desvios desses recursos não são raras .

Não é de hoje que a efetiva representatividade dessas entidades é questionada por muitos estudantes. Costa (2004, p. 196-206) mostrou que em diversos movimentos estudantis universitários do estado do Rio de Janeiro, na década de 1990, as entidades estudantis e, em particular a UNE, foram duramente criticadas. Muitos estudantes reivindicavam veementemente (como os nossos interlocutores) o fato de serem "independentes" e apartidários. A ex-deputada estadual Luciana Genro, em um depoimento sobre sua experiência de ensino médio justamente na cidade de Porto Alegre, evoca a fundação de uma UMESPA LIVRE, em 1985, como forma de questionar a legitimidade da entidade estudantil UMESPA, "que nada fazia para organizar os estudantes. Era um aparelho de MR8 ." (GENRO, 2000, p. 101). Mesquita (2003), estudando o movimento estudantil universitário de diversos estados do país no início dos anos 2000 , recolhe depoimentos de conteúdo e tom bastante similar ao que escutamos: as entidades seriam desnecessariamente burocráticas e hierarquizadas, distantes do cotidiano dos estudantes e seriam muito mais ligadas a partidos políticos do que elas assumem publicamente. Nos estudos que tratam dos movimentos de ocupação das escolas no Brasil (ver nota 4) não encontramos, no entanto, menção a essas críticas e às dissenções internas. Percebe-se com efeito, em diversos textos, uma postura militante, de adesão entusiasta aos ideias do movimento. Talvez por isso, aspectos menos "gloriosos", que mostram discórdias internas, tenham ganhado menos visibilidade .

Para muitos jovens, no entanto, opor-se às entidades era a principal luta. "É realmente algo que me repugna, assim, por dentro. Bah, foi uma das coisas que mais me puxou pra dentro do movimento, essa coisa das entidades", resume Caio. Cada jovem com quem conversamos tinha algo negativo a dizer sobre elas. David (17 anos, $3^{\circ}$ ano do ensino médio durante a ocupação), por exemplo, sugere:

Alguns que fazem parte de entidade, eles nem estudam de verdade. Seja lá qual cargo [que ocupem na entidade]... são pagos pra continuar estudando, continuar rodando, continuar no ensino técnico, no ensino médio, rodando e rodando pra não deixar de ser "secunda" e não sair daqui de dentro.

Podemos dizer que o grupo dos "independentes" durante as ocupações de escolas no Rio Grande do Sul tinham dois adversários: o governo (sobretudo estadual) e as entidades. Estas últimas representariam a "velha política", seriam "traidoras", "golpistas", seus membros seriam "politiqueiros", 
"pelegos", "ignorantes", "sem noção", "de direita", etc. Esses anátemas, termos acusatórios que explicitam um polo de repulsão do qual os jovens queriam se distanciar a qualquer custo, que gostariam de "banir" do seu mundo, revelam uma linha de fratura que nos parece suficientemente forte para falar de um "racha" interno a esse movimento. Se de longe, este - como outros movimentos sociais -, podem ser percebidos como relativamente homogêneos, acompanhando seu cotidiano as divergências internas vem inevitavelmente à tona.

Entender por onde passam as linhas de fratura de cada movimento, e aprender a se posicionar levando em conta essas divisões, permite aos participantes explicitar argumentos, desacordos, propostas, ideias e jeitos de fazer política. Contribui, assim, para a construção de uma identidade política (quem sou eu em política, e neste movimento? Em que eu acredito, o que eu quero fazer?, etc.). Como outras identidades, a identidade política se estabelece na confrontação, no conflito, no estabelecimento e manutenção de "fronteiras" (BARTH, 1969) entre um "nós" (para o Caio, eu como membro dos independentes; "nós", os independentes) e um "eles" (o governo, os "de direita" e também as entidades).

\section{VALENTINA, A "MÃE DA OCUPAÇÃO"}

Valentina cresceu vendo os pais, avós e tios maternos discutirem e participarem ativamente da vida política do país. Uma parte da família materna é afiliada ao PT e sua mãe era até alguns anos atrás: "eu me lembro pequena, eu tinha três, quatro anos quando o Lula ganhou. $E$ eu lembro eu desse tamaninho assim, e minha mãe me levando nos bandeiraços do PT". Aos 13 anos, diante das manifestações que levaram tantos brasileiros às ruas, ela começou a participar mais diretamente:

Eu via aquilo na televisão e me dava um negócio, eu tinha que ir, assim, desesperadamente! Altos discursos para poder convencer a família que tinham que me deixar. E daí a minha mãe, "Tá, vamos. Eu te levo no ato". Bah, eu quase chorei! (...) Daí eu comecei a ir assim, me apaixonei por aquilo. Eu lembro que num ato um dia, eu cheguei pra minha mãe e falei assim, "Mãe, eu tô me sentindo parte da história, mãe" (risos). Sério, e meio emocionada, sabe?

Apesar de ter crescido no mesmo ambiente, seu irmão um ano mais novo, Fred, outro líder da ocupação na Toledo, demorou a se interessar por esse universo. Ele nos explica que era mais próximo dos primos por parte de pai, que hoje ele percebe como sendo de direita: "Porque é assim, tem o pessoal que conhece a história, e tem o pessoal que é de direita. O pessoal do meu pai é de direita. $\mathrm{Na}$ família da minha mãe eles conhecem a história. Na época eu era mais ligado nos primos da parte do meu pai..." A irmã não perde a deixa para completar em tom provocativo: "E ele ficou sem conhecer a história por um bom tempo, tenho que dizer (risos)". Entrar na Toledo, na oitava série, foi o que fez Fred "virar a chave", nas palavras da irmã.

Desde então, Valentina participou de muitas manifestações, parou de alisar o cabelo ("uma coisa a menos que o sistema me impõe!, risos") e, em 2015, concorreu ao grêmio da escola mas perdeu as 
eleições. Em 2016, concorreu de novo e dessa vez ganhou, tornando-se a presidente. Fred integrava a chapa vencedora. Em abril daquele ano, uma parte dos professores entrou em greve e, como outros presidentes de grêmios, Valentina aderiu a ideia de juntar-se à paralização dos professores e passar a ocupar as escolas, apoiando-se no "capital militante" (MORENO; ALMEIDA, 2009; SEIDL, 2014; TOMIZAKI, 2013) que adquirira até ali. A decisão de efetivamente ocupar foi ancorada numa votação em assembleia, em que a maioria aprovou a ideia. Entre os presentes, no entanto, estavam aproximadamente 50 dos 675 alunos inscritos no ensino médio da escola.

Além do intenso envolvimento com a política, Valentina também partilha com os pais o fato de ser evangélica praticante. "Eu cresci nos dois ambientes", explica. Pouquíssimos estudantes sabiam da sua fé durante a ocupação, nós mesmas só soubemos mais tarde. Quase um ano depois, cursando artes visuais na FURG, ela tirou então a fé "do armário" e passou a postar mensagens explícitas, para não dizer fervorosas, em sua página Facebook. Em uma conversa em julho de 2017, abordamos o assunto e Valentina contou que, para ela, os dois engajamentos se alimentavam reciprocamente: "Na política eu tenho atitudes por causa disso [da religião] e na igreja eu levo também coisas do movimento. As duas coisas estão dentro de mim." Valentina contou, no entanto, que não se sentia nem um pouco à vontade para partilhar esse lado de sua vida com os colegas secundaristas: "Sabia que na ocupação eu tinha medo de falar? Poucas pessoas sabiam. Porque eu sabia que se eu falasse, assim abertamente, ia ter repressão. Isso é muito louco... Então eu ia escondido. Escondido do escondido do escondido."

Nessa mesma entrevista, realizada portanto quase um ano depois do final das ocupações, Valentina reflete sobre o talento de "conselheira" que lhe foi reconhecido durante a ocupação e a "força mental" que o movimento exigia: "Durante as ocupações, naqueles momentos mais difíceis, eu acho que eu tinha enlouquecido se eu não tivesse esse outro lado na minha vida... nossa, ajudou muito, emocionalmente falando entendeu?" De fato, durante as ocupações, muitos viam em Valentina um esteio. "A Valentina fazia todo mundo pensar um pouco, ela escutava, conversava, dava conselho... ela era tipo a mãe da ocupação" (Leo, $3^{\circ}$ ano do ensino médio durante a ocupação, em entrevista realizada em junho de 2017). Essas competências, valorizadas no âmbito da igreja, onde Valentina as praticava, aprendia e aperfeiçoava foram, na avaliação de seus colegas, fundamentais para que Valentina ocupasse o lugar de liderança que ocupou. A jovem teve acesso a diferentes espaços que a permitiram construir habilidades úteis a sua prática militante: a família politizada e evangélica, a sua participação direta em manifestações e assumindo papeis representativos na escola, e também a igreja. Ela mobilizava o que havia aprendido com essas experiências, embora soubesse que não podia explicitar, com seus colegas de ocupação, o papel que a igreja evangélica tinha cumprido na construção do seu jeito de se relacionar.

Uma das coisas que Valentina achava importante, durante a ocupação, era incentivar os ocupantes a incorporar na sua vida pessoal e nas suas atitudes cotidianas, as reivindicações políticas que afirmavam em público. Ela defendia, com um entusiasmo que a caracterizava, a coerência entre as convicções afirmadas e o jeito de ser de cada um. Falando de feminismo, por exemplo, ela disse: 
Ah porque agora a maioria das meninas, elas "ah eu sou feminista, sou feminista". Mas às vezes esse feminismo não condiz com a ação entendeu? (...) E os meninos também são muito..., eles enquadram sabe? Tipo, se uma menina arrota, eles olham, "hummm". Eu falo pra elas, cara, eu não preciso ficar depilando a perna, eu arroto na cara deles, eu grito tanto quanto eles, eu não sou aquela menina que fica com unha pintadinha...

Durante as ocupações, Valentina afirmava a importância de "marcar essa posição". Tanto na relação com os pais, na importância de se posicionar em casa (ela foi grande incentivadora de uma das meninas que se assumiu bissexual ), como na relação com os meninos:

É louco porque tu desconstrói eles. Eles não estão acostumados. Eles tão acostumados a falar mais alto que a menina, e a menina calar a boca, entendeu? Daí eu falava "tu tem que falar mais alto que eles, tu não pode deixar impor a voz. Gritou? Grita mais, levanta o dedo, bota a boca, grita, xinga, fala".

E minutos depois, ela completa: "Porque, ainda mais aqui dentro do movimento, os guris, todos eles falam, 'Ah eu não sou machista, eu sou o mais desconstruído'..." Aí na hora tu vê, que desconstruído o quê!" Nesse momento, estamos nós e ela rindo, e uma de nós comenta: "Porque agora tu só quer os descontruídos então..." E Valentina termina: "Só!! (risos) Tá todo desconstruidinho amor? Então vem cá!"

As ocupações em Porto Alegre terminam em junho de 2016, Valentina concluiu seu ensino médio no final daquele ano e, com a entrada na universidade, seu ativismo tem se concentrado cada vez mais na religião. Já seu irmão, Fred, mergulhou de cabeça na militância política. Contribuiu para o site Esquerda online e tornou-se um membro ativo do recém criado Mais - Movimento por uma Alternativa Independente e Socialista .

\section{DESCONSTRUIR O PRÓXIMO}

Se durante os anos 1990, houve uma retração dos movimentos feministas no Brasil (GOMES; SORJ, 2014), nos anos 2000 , e especialmente na última década, esses movimentos voltaram a ganhar força, graças, em grande parte, a ação militante de mulheres bastante jovens e de adolescentes (PINTO, 2003; ZANETTI, 2011). Nas ocupações de escolas de 2015 e 2016, em todo Brasil, a presença das meninas foi marcante: elas estiveram na linha de frente de passeatas, em embates diretos com a polícia, nas reuniões com representantes do governo, deram inúmeros depoimentos na mídia .

Porque as relações pessoais e íntimas entre homens e mulheres, de maneira geral, são ainda hoje marcadas por relações de poder desfavoráveis às mulheres, o movimento feminista tem incitado a refletir politicamente sobre essas relações. Durante a década de 1970, o mote "o pessoal é político" era uma bandeira do feminismo em diferentes países (PAGIS, 2014; MASCLET et al., 2018). Pagis mostra como as francesas que integraram maio de 1968 "politizaram aspectos da vida que até então eram 
consideradas como exteriores à esfera política, como a família, o lugar das mulheres na sociedade, o meio ambiente ou ainda a escola" (op. cit., p. 182). Essas reflexões e práticas de politização da esfera privada se inserem e alimentam um clima mais geral, um "ambiente cultural alternativo" (BENNETT, 2012, p. 20) que emerge, na Europa e sobretudo nos Estados Unidos, na segunda metade dos anos 1960. Ativistas que bebiam em fontes feministas, do movimento homossexual, anarquista e/ou situacionista passam a confrontar uma ideologia comunista mais "tradicional", que relegava a vida pessoal a um segundo plano, diante das prioritárias "luta revolucionária" e "luta de classes". Essa tendência à politização da intimidade, à não distinção entre anseios pessoais e reivindicações coletivas, que certos analistas denominam "política em primeira pessoa" (HUBER, 1985; CARVALHO, 2004), se consolida, no Brasil, nas décadas de 1980 e 1990, no contexto dos movimentos que surgem com o final da ditadura e a redemocratização do país (SCHERER-WARREN; KRISCHKE, 1987).

Quando Valentina, ou outros membros da ocupação, falam de "desconstruir" (a si mesmo, os outros, ser "desconstruído" como um objetivo), é um desejo semelhante que se percebe. Na relação com as colegas, Valentina se desespera com comportamentos de machismo interiorizado e as incita, como vimos, a responder, literalmente, à altura dos meninos ("Gritou? Grita mais"), a não deixar passar qualquer imposição de ideias, a não "se aquietar" ou "entrar num casulinho". Valentina encoraja também a fugir de padrões estéticos. O corpo e a aparência (o que fazer com os cabelos, com os pelos do corpo, com as unhas, como se vestir, etc.) são questões centrais para as feministas e o movimento negro, já que ele pode ser um lugar de materialização tanto da "alienação", como do "empoderamento" (LESNIK-OBERSTEIN, 2011; HORDGE-FREEMAN, 2017). Por fim, dentro do cotidiano do movimento, nas inúmeras decisões a tomar a cada dia, tanto no que se refere a posicionamentos da luta política, quanto da organização das tarefas da escola ocupada, Valentina, como certamente outras líderes feministas, bateram muitas vezes de frente com meninos da própria ocupação. Com Caio, os embates eram especialmente insistentes: ele era o protótipo do que Valentina chamava de "esquerdo-macho".

Valentina nos relata abaixo uma situação em que ela e outras meninas defendem um argumento semelhante aquele que sustentam as políticas de ações afirmativas (como aquelas de cotas para negros em vigor em diferentes universidades públicas do país, ou de cotas de gênero para garantir um percentual mínimo de mulheres candidatas a cargos políticos), e Caio se opõe a elas:

É que o Caio é uma pessoa que a gente está tentando desconstruir, mais nessa questão de feminismo, machismo... Aí teve uma discussão em uma das assembleias que foi a seguinte: "tá, quem vai falar com a mídia?" E daí uma menina falou, "tem que ser uma mulher", [e] ele, "por que tem que ser uma mulher?" Aí eu falei, "ué, porque quem fala, sempre, não são os homens? Não tem mulheres aqui que sabem muito bem tudo que tá acontecendo? Porque não dar abertura pra uma mulher, botar ela na frente?" E daí o Caio, de novo, "ah não concordo, eu acho que pode ser uma mulher, mas pode ser um homem também." Aí eu falei, "se for um homem, vai ser um homem negro, então!" (risos). Não, mas vocês não concordam? Porque daí eles ficam, sabe, querendo discutir... Eu, "gente, homens negros, mulheres negras e mulheres são oprimidas, pronto acabou, isso é um fato! Deu, não vou discutir mais isso, deu. Tua raça como homem hetero cis branco já pode acabar, tipo agora! (gargalhada). 
Nos parece que o que cansa Valentina, ela que já tem uma certa tarimba na militância, é uma atitude não muito reflexiva que por vezes seus companheiros podem adotar. Sugerir que poderia falar para a mídia, ou seja, representar o movimento, tanto um homem como uma mulher, ignorando ou deixando de lado o fato que há toda uma estrutura construída socialmente que dificulta o acesso de mulheres - e de pessoas negras - a cargos de responsabilidade, isso, nos parece, é o que frustra Valentina. Por trás dessa discussão travada pelos jovens, há uma série de questionamentos eminentemente políticos em sociedades democráticas: quem nos representa? Quem gostaríamos que nos representasse? Quem consegue aceder a lugares de representação e de poder? Qual espaço de representação deve ter uma minoria numa democracia (GOULD, 1996; SAWARD, 2010)? Questões que ecoam também, claro, quando o assunto são as entidades estudantis...

\section{CONCLUSÃO}

Antes da ocupação, Valentina e Caio conheciam-se apenas de vista. Tornaram-se amigos e aliados durante o movimento. Nem tudo eram flores entre eles no entanto. Duas figuras fortes, as provocações mútuas e os desacordos que, como vimos, eram frequentes, davam à relação um caráter "elétrico". Os retratos que fizemos desses dois jovens, evocando suas percepções e memórias, nos permitiram abordar pontos importantes do movimento de ocupação das escolas ocorrido no Rio Grande do Sul e em diferentes estados do país em 2016, do movimento estudantil atual no Brasil e, de maneira mais geral, trazem à tona questões relativas à juventude e participação política de jovens no Brasil hoje. Destacamos, neste texto, as aprendizagens decorrentes da participação nas ocupações, em especial a descoberta das diferentes tendências dentro do movimento: os "rachas" internos e a crítica às entidades de representação estudantil. Mostramos também a influência as reflexões feministas sobre esse movimento e, ao mesmo tempo, a diversidade de experiências que podem ter contribuído para forjar a prática militante de certos jovens. Valentina buscou na sua experiência na igreja evangélica um modelo de acolhimento de seus colegas.

Para finalizar, gostaríamos de voltar à expressão de Valentina e de outros jovens da ocupação que deu título ao artigo. Ser "desconstruído", "se desconstruir", "desconstruir" outros: o termo desconstrução e seus derivados são hoje usados em diversos movimentos sociais de esquerda, e em particular, nos movimentos feministas e LGBT. Como com outros termos (biopolítica e biopoder, hegemonia, descolonização ), houve visivelmente um empréstimo de noções produzidas no âmbito acadêmico. Jaques Derrida foi quem, na filosofia, conceitualizou de maneira mais sistemática, a partir da sua leitura de Heidegger, a noção de desconstrução. Inicialmente pensada como uma ferramenta de análise literária, ela foi em seguida associada ao pensamento crítico de um conjunto de autores franceses (Derrida, Deleuze, Guattari, Foucault, Baudrillard) cujos escritos pesquisadores norteamericanos agruparam sob a denominação de "French theory", classificando-os justamente de "desconstrucionistas". Esses pensadores franceses (eles mesmos engajados politicamente) influenciaram sobremaneira não só o pensamento acadêmico, mas um conjunto de movimentos sociais 
nos Estados Unidos e na América Latina, como o movimento negro, o feminista, LGBT, grupos antiimperialistas e anticapitalistas (CANAVESE, 2015; CUSSET, 2005; RAGO, 2014 ).

Pouco familiarizados com essas obras, os secundaristas recorrem à ideia de desconstrução, que se tornou comum - e quase incontornável - para jovens que participam de movimentos sociais de esquerda no Brasil. Para os nossos interlocutores, desconstruir(-se) significa quebrar padrões de comportamento que eles consideram arraigados, desestabilizar, desarrumar o status quo (das relações amorosas e familiares marcadas pelo machismo, das relações entre negros e brancos). Ser desconstruído é adotar uma atitude reflexiva, perceber o machismo em si mesmo, a submissão a uma ordem que não escolheram. Significa, como diziam, "parar de aceitar", parar de repetir, parar "de obedecer sem questionar". Se os secundaristas não deixaram de lado a aspiração de transformar estruturas sociais e instituições, o verbo desconstruir e sua forma pronominal, desconstruir-se, incarnam perfeitamente o entrelaçamento entre política e vida pessoal: a mudança que promulgam toma forma de um trabalho individual, sobre si mesmo ou dirigido a alguém próximo. Longe de utopias desencarnadas, a política do desconstruir é uma micropolítica do corpo e das relações cotidianas.

\section{REFERÊNCIAS}

1. ARREGUY, Marília Etienne. De "mortos-vivos" a "não-mortos": pensamento mágico, violência e insurgência nos protestos atuais. Educar em Revista, Curitiba, n. 64, p. 117-135, abr./jun. 2017.

2. BARGEL, Lucie. Jeunes socialistes / Jeunes UMP. Lieux et processus de socialisation politique. Paris: Dalloz, 2009.

3. BARTH, Fredrik. Introduction \& Pathan Identity and Its Maintenance. In: BARTH, Fredrik. Ethnic Groups and Boundaries: The Social Organisation of Culture Difference. Bergen/Londres: Universitetsforlaget/Allen \& Unwin, 1969. p. 9-38 e 117-134.

4. BENNETT, Andy. Pour une réévaluation du concept de contre-culture. Volume!, Nantes, v. 9, n. 1, p. 19-31, 2012.

5. CAMPOS, Antonia ; MEDEIROS, Jonas; RIBEIRO, Márcio. Escola de lutas. São Paulo: Ed. Veneta, 2016.

6. CANAVESE, Mariana. Los usos de Foucault en la Argentina. Recepción y circulación desde los años cincuenta hasta nuestros dias. Buenos Aires: Siglo XXI, 2015.

7. CATINI, Carolina de Roig; MELLO, Gustavo Moura de Cavalcanti. Escolas de luta, educação política. Educação \& Sociedade, Campinas, v. 37, n. 137, p.1177-1202, ago.-dez. 2016. 
8. CARVALHO, Isabel Cristina de Moura. A invenção ecológica: sentidos e trajetórias da educação ambiental no Brasil. Porto Alegre: Editora da UFRGS, 3a. éd., 2004.

9. COSTA, Carla de Sant'ana. Movimento estudantil contemporâneo: uma análise compreensiva das suas formas de atuação. 2004. 270f. Tese (Doutorado em Sociologia). Programa de PósGraduação em Sociologia, Universidade Federal de Pernambuco, Recife.

10. COSTA, Luciano Bedin da; SANTOS, Manuella Mattos dos. Espaços virtuais moventes das escolas ocupadas de Porto Alegre: apoio mútuo como base da inteligência coletiva. ETDEducação Temática Digital, Campinas, v. 19, n.1, p. 49-72, jan./mar. 2017.

CUSSET, François. French Theory: Foucault, Derrida, Deleuze \& Cie et les mutations de la vie intellectuelle aux États-Unis. Paris: Éditions La Découverte, 2005.

FILLIEULE, Olivier. Carrière militante. In: FILLIEULE, Olivier; MATHIEU, Lilian; PÉCHU, Cécile (orgs.). Dictionnaire des mouvements sociaux. Paris: Presses de Science Po, 2009. p.656. (orgs.). Julinho: 100 anos de história. Porto Alegre: Editora Age, 2000. p. 100-101. GOMES, Carla; SORJ, Bila. Corpo, geração e identidade: a Marcha das vadias no Brasil. Revista Sociedade e Estado, Brasília, v. 29, n. 2, p.433-447, Mai.-ago. 2014.

GOMES, Simone da Silva Ribeiro; GÓMEZ-ABARCA, Carlos. \#Ocupaescola, \#Ocupatudo. Experiencias políticas de estudiantes de secundaria en el 2016, en Río de Janeiro, Brasil. Revista Latinoamericana de Ciencias Sociales, Niñez y Juventud, Manizales (Colômbia), v. 16, n. 2, p. 825-838, ago. 2018. GOULD, Carol. Diversity and Democracy: Representing Differences. In: BENHABIB, Seyla (org.). Democracy and Difference: contesting the Boundaries of the Political. Princeton: Princeton University Press, 1996. p.171-186.

17. HARVEY, David; DAVIS, Mike; ŽIŽEK, Slavoj; ALI, Tariq; SAFATLE, Vladimir Pinheiro. Occupy!: movimentos de protesto que tomaram as ruas. São Paulo: Boitempo e Carta Maior, 2012.

18. HORDGE-FREEMAN, Elizabeth. Contesting Black Beauty: Afro-Aesthetics, Beauty Competitions and Racial Resistance in Brazil, ReVista The Harvard Review of Latin America, Cambridge (MA), 2017, [on line]. Disponível em: <https://revista.drclas.harvard.edu/book/contesting-beauty>. Acesso em 20/08/2019. 
HUBER, Joseph. Quem deve mudar todas as coisas: as alternativas do movimento alternativo. Rio de Janeiro: Paz e Terra, 1985. University Press, 2011.

21. MANGUINHO, Julyana. Protagonismo feminino no contexto escolar: entre negociações, enfrentamentos e tensões. Seminário Internacional Fazendo Gênero 11 \& 13th Women's Worlds Congress (Anais Eletrônicos), Florianópolis, 2017. Disponível em:

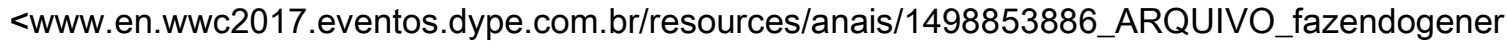
o.pdf. Acesso em 20/08/2019.

MARTINS, Karine J. (2017). A vez das minas: as ocupações sob o olhar feminista na mídia alternativa. Seminário Internacional Fazendo Gênero 11 \& 13th Women's Worlds Congress (Anais Eletrônicos), Florianópolis, 2017. Disponível em: <www.en.wwc2017.eventos.dype.com.br/resources/anais/1499467059_ARQUIVO_MARTINS-KJAvezdasminas.pdf>. Acesso em 20/08/2019.

MARTINS, Marcos Francisco; FÁBIO, Alexandre Tardelli Filho; KEYLA, Priscilla Rosado Pereira; ÉRICO, Vinicius Fonseca dos Santos. Entrevista. As ocupações das escolas estaduais da região de Sorocaba/SP: falam os estudantes secundaristas. Crítica Educativa, Sorocaba, v. 2, n. 1, p. 227-260, 2016.

24. MEDAETS, Chantal; MÉZIE, Nadège; CARVALHO, Isabel Cristina de Moura. "De cabeça e com o coração": o fazer política de jovens ocupantes das escolas estaduais de Porto Alegre (maio e junho 2016). In: MEDAETS, Chantal; FONSECA, Claudia; RIBEIRO, Fernanda Bittencourt (orgs.). Pesquisas sobre família e infância no mundo contemporâneo. Porto Alegre: Sulina, 2018. p. 130152.

MESQUITA, Marcos Ribeiro. Movimento estudantil brasileiro: Praticas militantes na ótica dos Novos Movimentos Sociais. Revista Critica de Ciencias Sociais, Coimbra, v.66, p.117-149, 2003. institucionalização dos movimentos sociais. Pro-Posições, Campinas, v. 20, n. 2, p. 59-76, 2009.

27. NOVAES, Regina. \#OcupaEscola: a renovação da participação juvenil. Teoria e debate, Rio de Janeiro, $\quad$ n. 148 [online], 2016.2 Disponível em: <https://teoriaedebate.org.br/2016/05/25/\%EF\%BB\%BFocupaescola-a-renovacao-daparticipacao-juvenil/>. Acesso em 20/08/2019. 

Occupy! A Global Movement. Londres/New York: Routledge, 2015.

31. Iluminuras, Porto Alegre, v. 18, n. 44, p. 265-283, 2017. PINTO, Céli Regina J. Uma história do feminismo no Brasil. São Paulo: Fundação Perseu Abramo, 2003.

33. 2014 Adriano. As ocupações de escolas públicas em São Paulo (2015-2016): entre a posse e o direito à manifestação. Novos estudos CEBRAP, São Paulo, p. 291-310, mai.-ago. 2018.

40. TILLY, Charles. Contentious Repertoires in Great Britain. In: TRAUGOTT Mark (org.). Repertoires and Cycles of Collective Action. Durham: Duke University Press, 1995. p.15-42. 
41. TOMIZAKI, Kimi. Deux générations de syndicalistes au Brésil: pratiques quotidiennes et formation politique. Actes de la recherche en sciences sociales, Paris, v. 1, n. 196-197, p. 102-113, 2013.

42. VENDRAMIN, Patricia. L'engagement militant: la rencontre entre un individu, une cause et une organisation. In: VENDRAMIN, Patricia. L'engagement militant. Louvain: Presses Universitaires de Louvain, 2003. p.15-34.

43. ZANETTI, Julia Paiva. Jovens feministas do Rio de Janeiro: trajetórias, pautas e relações intergeracionais. Cadernos Pagu, Campinas, v. 36, p. 47-75, 2011.

\section{DOCUMENTÁRIOS:}

1. COLOMBINI, Flavio; ALONSO, Beatriz. Lute como uma menina. 2016.

Disponível em: <https://www.youtube.com/watch?v=8OCUMGHm2oA>. Acesso em 20/08/2019.

2. CAPAI, Eliza. Espero tua (re)volta. 2019.

\section{Chantal Medaets}

Pós-doutoranda na Faculdade de Educação da Unicamp (desde dezembro de 2018). Graduada em Pedagogia (PUCSP, 2003), possui mestrado (2009) e doutorado (2015) em Educação pela Universidade Paris Descartes.

\section{Nadège Mézié}

Possui graduação em Sociologia e em Antropologia (2002), mestrado em Antropologia (2004) e doutorado em Antropologia (2011) pela Universidade Paris Descartes (doutorado e mestrado reconhecidos pela UFRGS). Realizou pós-doutorado no Programa de Pós-graduação em Antropologia Social da UFRGS (2015-2016).

\section{Isabel Cristina de Moura Carvalho}

Isabel Cristina de Moura Carvalho tem graduação em Psicologia pela Pontifícia Universidade Católica de São Paulo (1984), especialização em psicanálise pela Universidade Santa Úrsula, RJ (1990), mestrado em Psicologia da Educação pela Fundação Getúlio Vargas, RJ (1989) e doutorado em Educação pela Universidade Federal do Rio Grande do Sul (2001). Pós-doutorado em antropologia na Universidade de San Diego, Califórnia (UCSD), de fevereiro/2006 à fevereiro/2007. 


\section{Como citar este documento:}

MEDAETS, Chantal; MÉZIÉ, Nadège; CARVALHO, Isabel Cristina de Moura. "Todo desconstruidinho": jovens líderes do movimento estudantil Ocupa Tudo RS. Reflexão e Ação, Santa Cruz do Sul, v. 27 , n. 3, p. 143-159, oct. 2019. ISSN 1982-9949. Disponível em: <https://online.unisc.br/seer/index.php/reflex/article/view/13592>. Acesso em: doi:https://doi.org/10.17058/rea.v27i3.13592. 